\title{
Analysis of Effectiveness of Interphase Transfer in a Case of Purification of Biogas in Microbubbling Equipment with a Consideration of Chemisorption of Carbon Dioxide
}

\author{
Botagoz Myrzakhmetovna Kaldybaeva ${ }^{1}$, Alisher Evadilloevich Khusanov ${ }^{1}$, Darkhan Sabyrkhanovich \\ Sabyrkhanov $^{1}$, Marat Isakovich Satayev ${ }^{1} \&$ Zakhangir Evadilloevich Khusanov $^{1}$ \\ ${ }^{1}$ Auezov South Kazakhstan State University, Kazakhstan \\ Correspondence: Botagoz Myrzakhmetovna Kaldybaeva, Auezov South Kazakhstan State University, \\ Kazakhstan.
}

Received: January 15, 2015 Accepted: February 3, 2015 Online Published: July 30, 2015

doi:10.5539/mas.v9n8p221 URL: http://dx.doi.org/10.5539/mas.v9n8p221

\begin{abstract}
The presented paper describes energy saving technology of biogas purification by microbubling method Description of a new design of microbubling equipment for gas-liquid solution and mathematical simulation of a process during chemisorption of carbon dioxide are presented. Experimental studies of mass transfer characteristics of microbubling equipment, based on model systems, were conducted with an aim to define a possibility of application of microbubling process for removal of carbon dioxide from biogas in order to obtain highly concetrated metane. As a result of the study optimal process parameters are defined, key factors affecting mass transfer characteristics of membrane microbubling method are also established. Efficiency of membrane microbubling equipment from the point of view of interphase mass transfer is assessed.
\end{abstract}

Keywords: biogas, microbubling equipment, tubular ceramic membranes, highly concentrated methane, unconventional energy sources, mathematical simulation, mass transfer, liquid, gas, microbubbles

\section{Introduction}

Currently, Kazakhstan has enormous potential for a development of agriculture, vast territories allows that country to become a leading country, both in livestock and in crops production. In order to achieve that goal, it is necessary to implement the most advanced technologies and innovations in a field of biogas implementation for energy needs by means of processing livestock wastes in biogas equipment, as a result the following products can be obtained: biogas, mineralized nitrogen fertilizer, methane, carbon dioxide, electricity, heat energy. Therefore, rational use of agricultural waste products is todays important problem, if it's solved, there is anenormous potential for an implementation of biomass for a production of liquid and gaseous fuel (biogas), which will allow companies to reduce expenses related with use of electric energy and fertilizers, as well environment related taxes, aimed to a reduction of a contamination of water bodies, a contamination of soil with pathogenic bacteria and helminths, which are contained in manure flows of livestock farms. Thus, it allows to reduce cost of products.

Biological processing is not something novel nowadays. It is already widely used throughout the world, but, largely, as a way to recycle a large amount of wastes of agricultural and food industries, and as an alternative source of energy, which is one of possible solutions to a deficit of energy sources (Rutz, \& Janssen, 2014), (Steinhauser, 2008). This method essentially consists of anaerobic expansion of organic wastes, mainly, produced by farms, food production facilities and sewage systems. As a result of vital activity of micro-organisms, wastes are recycled with a formation of mixture of gases (so-called biogas) and their volume is reduced. Biogas, obtained by anaerobic decomposition of wastes, contains methane $(\approx 60 \%(\mathrm{vol})$.$) and carbon$ dioxide $(\approx 40 \%($ vol. $))$. Resulting products, which are biogas and half fermented semiliquid substance, are of great value as gaseous fuel and organic fertilizer. The gas contains hydrogen sulphide, ammonia, water vapor; its calorific value is quite low $-19.5-19.8 \mathrm{MJ} / \mathrm{m}^{3}$ and burning of such gas may cover only a small portion of energy needs. After purification and drying, gas must contain not less than $98 \%$ (vol.) of $\mathrm{CH}_{4}$ (calorific value is not less than $33.0 \mathrm{MJ} / \mathrm{m}^{3}$ ), a concentration of $\mathrm{N}_{2} \mathrm{~S}$ should not exceed (Biogas plants in Europe: A practical handbook, 2007), (Eder, \& Schulz, 2006), (Ditnerski, et al., 1991) 10 $0^{-4} \%$ (3-5 million $\left.{ }^{-1}\right)$. Separation of components and 
production of highly concentrated methane is a big problem, which is still not solved (Christensen, et al., 1996), (Concise Encyclopedia of Bioresource Technology, 2004), (Kimura, 1980). Cost-effectiveness of biogas equipment is of certain interest in a context of agricultural enterprises, taking into account an integrated use of biogas as energy source and fertilizer in agriculture. Nowadays, in the world there is a large interest for problems of methane fermentation of manure wastes and other organic wastes. In addition to an equipment, which includes fermentation chambers, gasholder and storage for half-fermented substance (sludge), it is also necessary to widely implement a technology of methane concentration using methods of separation of multi-component gases.

Use of well-known methods of gas separation (Ditnerski, et al., 1991), (Christensen, et al., 1996), (Concise Encyclopedia of Bioresource Technology, 2004), (Kimura, 1980) in that case is ineffective and requires a development of new methods of purification. An alternative way of solving that problem is a combination of membrane and absorptive processes.

Recently, scientific community of developed countries of the West (Atchariyawut et al, 2007), Japan (Kukizaki, \& Goto, 2006 (a), (Kukizaki, \& Goto, 2006b) produced a number of publications, reporting that during a dispersion of a gas through porous membranes microbubbles are formed (Rodriguez, \& Rubio, 2014), (Zong, et al., 2006), (Kim, et al., 2000), (Cho, et al., 2005) with dimensions of 0.5-150 $\mu \mathrm{m}$. As a result of such small sizes, microbubbles have a number of unique properties, such as increased contact surface of interacting phases, they can be widely applied in chemical (Loubiere, \& Hebrard, 2004), (Painmanakul, et al., 2005), food and pharmaceutical (Unger, et al., 2003) industries, as well as in biotechnology, medicine and unconventional energy production.

As can be seen from the presented review, study of gas purification with a formation of microbubles is currently still cannot be considered complete, as an integrated approach, i.e. physical and mathematical simulation, as well as design of gas separating equipment, which provides formation of microbubles and its use for purification of biogas from carbon dioxide emissions with an aim to increase methane concentration, is expected to provide new and important results in that field.

The development of technology, which allows to increase concentration of methane through a development of interphase surface, using unique microbubles properties during fine dispersion of gases, will lead to an entirely new high-efficient equipment of gas-liquid contact type, including new types of reactors and fermenter. At the same time, a preparation of biogas (removal of $\mathrm{CO}_{2}, \mathrm{H}_{2} \mathrm{~S}$ and further compression for storage and distribution to consumers) using a the developed microbubling equipment can provide a significant economic effect, as compared to traditional methods, for example, absorption and adsorption. The are several variants of process organization, for each of which defined parameters are required surface of membranes, cost of compression, degree of methane extraction from original mixture in different conditions. As a result of separation concentration of methane in fuel gas reaches $98 \%$ (vol.).

The problem includes a design of microbubling equipment and effective purification technology for biogas by means of a substantial development of surface of phases in gas-liquid system. The solution of those problems lies in dispersion of biogas components through membrane in fluid, its inertia effects forming dispersion of nano- and micro-bubles, resulting in significant increase of phase interface surface for separation of highly-concentrated methane.

Due to ultra small size of generated microbubes, microbubling membrane process can be used as a basis for a development of a highly efficient biogas purification technology. In the same time, it is possible that there are no disadvantages related to limiting of loads by gas and liquid for such a technology. Unique properties of microbubles during fine dispersion of gases allows to implement that technology also in oil and gas and mining industries for a purification of associated gas and mining gas, as well as in fields of biotechnology and pharmaceutics.

Mathematical simulation of dispersion mechanics of biogas components in the developed technology of separation of highly-concentrated methane from biogas and a definition of a relationship of main mass transfer parameters, i.e. specific interphase surface, interphase flow of absorbed substances $\left(\mathrm{CO}_{2}, \mathrm{H}_{2} \mathrm{~S}, \mathrm{NH}_{3}\right.$ etc.), mass transfer coefficients, and speed of fluid and concentration of active part of absorbent in microbubling processes are not established so far, which makes it a topical problem.

The developed process of biogas purification with an aim to obtain highly-concentrated methane in microbubling equipment allows to eliminate unfavourable influence of bioenergetics on environment: emission of solid particles, carcinogenic and toxic substances, carbon dioxide, biogas, biospirit, impoverishment of organic components of soils, exhaustion and erosion of soils, explosion risk, large number of wastes in a form of 
by-products (waste waters, distillation residues).

\section{Theoretical Analysis}

Analysis of features of mass transfer processes in microbubling equipment allows to conclude, that in a case of a design of an equipment by a type of shell-and-tube module, average time of presence of microbubles in apparatus is quite small. In that case, considering that the flow's structure in an equipment is close to perfect displacement model (PDM), average time of presence can be calculated as follows: $t_{p r}=\frac{l}{2 \omega}$. Considering standard length of ceramic membranes of $0.8 \mathrm{~m}$ and fluids' speeds of 1-3 m/s, time of presence is $0.1-0.4 \mathrm{~s}$, the time limit might be not enough for effective physical absorption. However, in a case of chemisorption, time of gas-liquid reaction is of $0.01 \mathrm{~s}$ magnitude (Astarita, 1971). Thus, from a point of view of effectiveness of mass transfer processes in membrane module, the most prospective are chemisorption processes in a case of comparatively fast chemical reaction. Moreover, membrane microbubling equipment can be used not only as absorbers, but also as chemical reactors. Thus, from a point of view of study of interphase mass transfer in microbubling contactor, it is necessary to discuss main existing chemisorption theories.

Two directions in a development of chemisorption theory can be marked out, they are based on two models of mass transfer. The first direction is based on film theory of Uitmen and is developed in works of Hatta (Hatta, 1932) and Van Krevelen (Krevelen, \& Hoftijzer, 1958). The second direction is based on a penetration theory, it discuses non-stationary process of absorption during continuous renovation of interphase surface. That direction is mainly developed in works of Danckwerts (Danckwerts, 1973). It's worth mentioning, that all existing models can't be considered complete and posses a number of disadvantages and number of studies, which would allow to select one of the directions, is insufficient. At the same time, in some practical cases, results, obtained by means of different models, are virtually the same.

So far there is no data on studies of interphase mass transfer during membrane dispersion of gas. That data would allow to compare effectiveness of mass transfer equipment. Hence, the presented study is dedicated to experimental study of mass transfer in membrane microbubling contactor on an example of $\mathrm{CO}_{2}$ absorption by $\mathrm{CaO}$ suspension. $\mathrm{CaO}$ content in the suspension is $10-20 \%$ (mass).

Study of interphase mass transfer in the presented study was carried out on an example of chemisorption of carbon dioxide by alkali solutions of various concentrations, in order to do that the method, proposed by Danckwerts and Sharma was used (Sharma, \& Danckwerts, 1970).

The process comprises two consecutive reactions:

$$
\begin{aligned}
\mathrm{CO}_{2}+\mathrm{OH}^{-} & =\mathrm{HCO}_{3}^{-} \\
\mathrm{HCO}_{3}^{-}+\mathrm{OH}^{-} & =\mathrm{CO}_{3}{ }^{2-}+\mathrm{H}_{2} \mathrm{O}
\end{aligned}
$$

Thus, total reaction is occurring according to the formula:

$$
\mathrm{CO}_{2}+2 \mathrm{OH}^{-}=\mathrm{CO}_{3}{ }^{2-}+\mathrm{H}_{2} \mathrm{O} \text {. }
$$

In a case of sufficient excess of alkali, the second reaction is occuring almost momentarily, that's the process is limited by the first reaction, which is speed is defined by means of the expression:

$$
\mathrm{N}_{\mathrm{R}}=k_{2}\left[\mathrm{CO}_{2}\right]\left[\mathrm{OH}^{-}\right] \text {. }
$$

Thus, in a case of excess of $\mathrm{OH}^{-}$ions, the reaction can be considered as a reaction of pseudo-first order (Sharma, $\&$ Danckwerts, 1970). According to the main mass transfer equation, molar flow of $\mathrm{CO}_{2}$ from phase to phase can be defined as follows:

$$
M=k_{y}\left(C_{0, G}-C_{i, G}\right) F=k_{x}^{\prime}\left(C_{i, L}-C_{0, L}\right) F,
$$

where $k_{y}, k_{x}^{\prime}$ - coefficients of mass transfer in gas and liquid phases respectively, $C_{0, G}-\mathrm{CO}_{2}$ concentration in a volume of gas phase, $C_{i, G}-\mathrm{CO}_{2}$ concentration in gas phase in interphase border, $C_{0, L}-\mathrm{CO}_{2}$ concentration in a volume of liquid phase, $C_{i, L}-\mathrm{CO}_{2}$ concentration in liquid phase in interphase border, $F$ - interphase surface area. If chemical reaction is fast enough, it can be accepted that $C_{0, L}=0$, considering that concentrations in interphase surface are related by equilibrium $-C_{i, G}=m C_{i, L}$, the following can be obtained from expression (5): 


$$
M=\frac{G_{0, G} F}{\left(\frac{1}{k y}+\frac{m}{k_{x}^{\prime}}\right)} .
$$

In the following, let's discuss the solution, leading to expression for mass transfer coefficient for chemisorption. The discussed reaction is very fast nonreversible chemical reaction in liquid phase of the following type (Hatta, 1932):

$$
v_{A} A+v_{b} B \rightarrow v_{d} D,
$$

At the same time, it's considered that reaction zone starts directly in a vicinity interphase surface and, depending on speed of reaction and concentration of components, is extended on a different depth. The process is considered stationary. The solution can be applied to reaction of first (of $A \rightarrow v_{d} D$ type) and pseudo-first type.

In a case of nonreversible reaction of first order $n$ by substance $A$, equation of convective diffustion will take the following form (Richardson, \& Coulson, 1999):

$$
D_{A} \frac{d^{2} C_{A}}{d y^{2}}=k_{P} C_{A}^{n}
$$

where reaction speed constant $k_{P}$ is defined according to expression $k_{P}=k_{n+m} C_{B}^{m}$, in which $k_{n+m}-$ reaction speed constant of order of $n+m$. Boundary conditions:

$$
\begin{array}{cc}
y=0 & C_{A}=C_{A i} \\
y=\infty & C_{A}=0
\end{array}
$$

By means of specifying $\frac{d C_{A}}{d y}=q$, expression (8) can be presented in the following form:

$$
q \frac{d q}{d C_{A}}-\frac{k_{P}}{D_{A}} C_{A}^{n}=0
$$

Integration of that expression considering boundary conditions leads to the expression:

$$
\left(\frac{d C_{A}}{d y}\right)^{2}=\frac{2}{n+1} \frac{k_{P}}{D_{A}} C_{A}^{n+1}
$$

Because $\frac{d C_{A}}{d y}$ is negative:

$$
\left(\frac{d C_{A}}{d y}\right)=-\sqrt{\frac{2}{n+1}} \sqrt{\frac{k_{P}}{D_{A}}} C_{A}^{\frac{n+1}{2}} .
$$

Thus, interphase chemisorption speed can be defined as follows:

$$
N_{A}^{\prime}=-D_{A}\left(\frac{d C_{A}}{d y}\right)_{y=0}=\sqrt{\frac{2 k_{P} D_{A}}{n+1} C_{A i}^{\frac{n+1}{2}}} .
$$

In a case chemical reaction of first (or pseudo-first) order is not fast enough, $C_{A 0} \rightarrow 0$, and from expression (12) it follows, that chemisorption speed can be calculated as follows:

$$
N_{A}^{\prime}=\sqrt{k_{P} C_{A i} D_{A}}
$$

Then, considering, that in a case of fast enough reaction $C_{A 0}=0$, the following expressing for coefficient of mass transfer for absorption, which is accompanied by reaction of pseudo-first order (also, considering that the reaction has the first order by substance $B$ ):

$$
k_{x}^{\prime}=\frac{N_{A}^{\prime}}{\left(C_{A i}-C_{A 0}\right)}=\sqrt{k_{p} D_{A}}=\sqrt{k_{2} C_{B} D_{A}}
$$

In all relationships presented above it is presumed, that substance $B$ is in excess and $C_{B}=$ const. In the study (Krevelen, \& Hoftijzer, 1958) an investigation into influence of concentration of $C_{B}$ on ration of values $\frac{k_{x}^{\prime}}{k_{x}}$ and $\frac{\sqrt{k_{2} C_{B} D_{A}}}{k_{x}}$ (as $C_{B}$ an average value is used). The studies were carried out using carbon dioxide - sodium hydroxide, results are presented in Figure 1. 


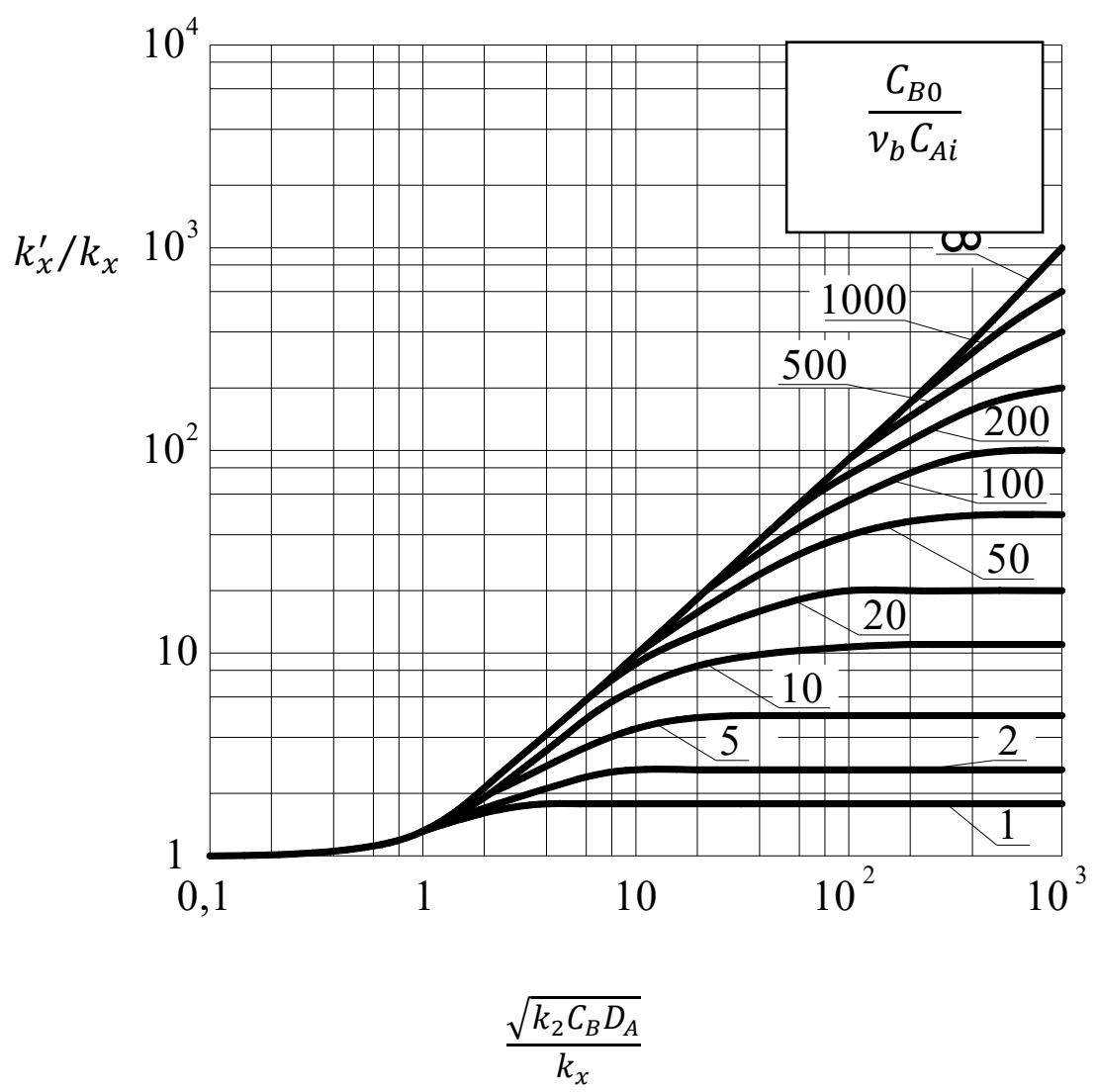

Figure 1. Relationship of value $\frac{k_{x}^{\prime}}{k_{x}}$ from $\frac{\sqrt{k_{2} C_{B} D_{A}}}{k_{x}}$ with different values $\frac{C_{B 0}}{v_{b} C_{A i}}$.

Analysis of the diagram shows, that even in a case of slow reaction, independently of concentration B, value of $\frac{k_{x}^{\prime}}{k_{x}} \approx 1$ and process are close to physical absorption. Increase of reaction speed leads to that value of $\frac{k_{x}^{\prime}}{k_{x}}$ becomes approximately equal to $\frac{\sqrt{k_{2} C_{B} D_{A}}}{k_{x}}$, which demonstrates a possibility of application of expression (14) for calculation of mass transfer coefficient. In that area the process is limited by speed of chemical reaction. With a further increase of speed value of $\frac{k_{x}^{\prime}}{k_{x}}$ becomes constant, which is close to $\frac{C_{B 0}}{v_{b} C_{A i}}$, at the that, the process is limited by mass transfer $\mathrm{B}$ to reaction zone.

According to aforementioned points, expression (5) can be used with acceptable accuracy in the following range:

$$
5<\frac{\sqrt{k_{2} C_{B} D_{A}}}{k_{x}}<\left(\frac{C_{B}}{v_{b} C_{A i}}\right)
$$

where $k_{x}$ - mass transfer coefficient for physical absorption. Substitution of expression (14) in expression (6), considering that $\mathrm{F}=\mathrm{aV}_{\text {work }}$, produces the following:

$$
M=\frac{C_{0, G} a V_{\text {work }}}{\left(\frac{1}{k y}+\frac{m}{\sqrt{k_{2} C_{B} D_{C O_{2}}}}\right)}
$$

Expression (16) can be transformed in the following form: 


$$
\frac{C_{0, G} V_{\text {work }}}{M}=\frac{1}{k_{y} a}+\frac{m}{a \sqrt{k_{2} C_{B} D_{C O}}}
$$

In coordinates $y=\frac{C_{0, G} V_{\text {work }}}{M}, x=\frac{m}{\sqrt{k_{2} C_{B} D_{C O_{2}}}}$ expression (17) describes line with angle of inclination tangent $\frac{1}{a}$ and crossing with coordinate axis in point $\frac{1}{k_{y} a}$. Thus, by means of experimental study of relationship of $y$ from $\mathrm{x}$ specific interphase surface area in equipment can be defined, as well as mass transfer coefficient in gas phase, which allows to define effectiveness of interphase mass transfer in membrane microbubling equipment.

Following conclusion can be made on a basis of analysis of mass transfer with chemical reaction: existing theories regarding chemisorption, event though they can't be considered complete, provide sufficiently reliable results for a case of fast nonreversible reactions of first and pseudo-first order. At the same time, in fact, all models of mass transfer are demonstrating similar values for mass transfer coefficient for chemisorption. However, because an implementation of expression (4) requires conforming with condition (15), it is necessary to carry out additional experimental studies in order to define value of $k_{x}$. For conditions, specified by inequality (15), coefficient of mass transfer may be calculated according to expression $k_{x}^{\prime}=\sqrt{k_{P} D_{A}}=$ $\sqrt{k_{2} C_{B} D_{A}}$, which is conforming both with film and penetration theories. The expression shows, that in a case of fast chemical reaction, mass transfer coefficient doesn't depend on hydrodynamic conditions in flow core, but it is defined by speed of reaction and speed of diffusion of absorbed component.

\section{Methodology}

At the first stage of anaerobic half-fermenting of organic substances by means of biochemical decomposition (hydrolysis), first, decomposition of high-molecular compounds (carbohydrates, fats and proteic substances) into low-molecular compounds takes place (Rutz, \& Janssen, 2014), (Christensen, et al., 1996), (Concise Encyclopedia of Bioresource Technology, 2007). At the second stage, with acid-forming bacteria taking part in the process, further decomposition with a formation of organic acids and their salts occurs, as well as spirits, $\mathrm{CO}_{2}$ and $\mathrm{H}_{2}$, then $\mathrm{H}_{2} \mathrm{~S}$ and $\mathrm{NH}_{3}$. Final bacterial transformation of organic substances in $\mathrm{CO}_{2}$ and $\mathrm{CH}_{4}$ is carried out at the third stage of the process (methane fermentation). In addition, additional amount of $\mathrm{CO}_{2}$ and $\mathrm{CH}_{4}$ is formed in further from $\mathrm{CO}_{2}$ and $\mathrm{H}_{2}$. Those reaction occur simultaneously, at that, methane -forming bacteria form a significantly higher requirements for existence condition, as compared to acid-forming bacteria. For example, they require absolutely anaerobic media and longer time for reproduction. Speed and scaled of anaerobic fermentation of methane-forming bacteria depend on their metabolic activity.

For the study of interphase mass transfer during chemisorption of carbon dioxide by $\mathrm{CaOH}$ solution in membrane contactor, the method proposed by Sharma and Danckwerts was selected (Sharma, \& Danckwerts, 1970).

Molar flow of absorbed $\mathrm{CO}_{2}$ in that study was experimentally defined by means of a change of concentration of alkali in solution, the following expression was used for calculations:

$$
M=\frac{\left(C_{B}^{H}-C_{B}^{K}\right) V_{L}}{v_{b}}
$$

where $C_{B}^{H}$ and $C_{B}^{K}$ - initial and final alkali concentration, $V_{L}$ - consumption of solution, $v_{b}-$ stoichiometric coefficient in overall equation, which is equal to 2 .

Reaction speed constant of second order $\mathrm{k}_{2}$ can be calculated using the following expression (Pohorecki, \& Moniuk, 1988):

$$
\lg \left(\frac{k_{2}}{k_{2, \infty}}\right)=0.221 I-0.016 I^{2}
$$

Value of speed constant in infinitely diluted solution is defined as follows:

$$
\lg \left(k_{2, \infty}\right)=11.895-\frac{2382}{T}
$$

Expression (20) can be used in temperature range 290-314 K. Ionic force is calculated according to the following expression (Darmana, et al., 2007): 


$$
I=\frac{1}{2} \sum_{j=1}^{n} C_{j} Z_{j}^{2}
$$

where $C_{j}$ - concentration of $\mathrm{Ca}^{+}, \mathrm{HCO}_{3}^{-}, \mathrm{OH}^{-}, \mathrm{CO}_{3}{ }^{2-}$ ions, $\mathrm{Z}_{\mathrm{j}}$-valence of those ions. At the same time, it is noted (28) that, because of $\mathrm{HCO}_{3}{ }^{-}$and $\mathrm{CO}_{3}{ }^{2-}$ ions' concentration are quite small, their values can be neglected. Thus, value of I becomes equal to concentration of alkali in a solution.

Diffusion coefficient $\mathrm{CO}_{2}$ in alkali solution is defined according to the following equation (Bobilev, 2003):

$$
D_{\mathrm{CO}_{2}}=D_{\mathrm{CO}_{2}}^{a q}\left(\frac{\mu_{a q}}{\mu_{s}}\right)^{0.85}
$$

where $\mu_{a q}$ - viscosity of water, $\mu_{s}$ - viscosity of alkali solution (was defined according to the data (Бобылев, 2003)), $\mathrm{CO}_{2}$ diffusion coefficient in clear water is defined as follows (Versteeg, \& Swaaij, 1988):

$$
D_{\mathrm{CO}_{2}}^{a q}=2.35 \cdot 10^{-6} \exp \left(-\frac{2119}{T}\right) \text {. }
$$

Distribution coefficient $\mathrm{m}$ was defined on a basis of experimental data on solubility of carbon dioxide in solutions of $\mathrm{CaOH}$, presented in (28). In experiments on membrane with average pore diameter of $0.5 \mu \mathrm{m}$, in a case of alkali concentrations of $0.030-0.070 \mathrm{kmole} / \mathrm{m}^{3}$, value of $\mathrm{m}=10.3$ was used, in experiments on membrane with average pore diameter of $2.6 \mu \mathrm{m}$, in a case of alkali concentrations of $0.014-0.030 \mathrm{kmole} / \mathrm{m}^{3}$, value of $\mathrm{m}=9.9$ was used,

\section{Results of Experimental Studies}

The experimental studies, which were carried out in the presented work, were aimed at a definition of main mass transfer characteristics of membrane microbubling process..

From the point of view of interphase mass transfer, the objects of the study were realtionships of interphase molar flow of absorbed substance, mass transfer coefficients in gas and liquid media, as well as specific interphase surface area from speed of liquid in membrane module and from concentration of active part of absorbent. The goal of the experimennts was data for an estimation of effectiveness of interphase mass transfer in membrane microbubling contactor and its comparison with mass transfer equipment of other types.

For study of mechanisms of gas-liquid reaction in a case of microbubling the process of carbon dioxide chemisorption by $\mathrm{CaOH}$ solutions of various concentrations was selected. Because of small content of surfactants, physical properties of liquid phase (viscosity, density) were accepted the same as for clean water. Carbon dioxide and biogas mixture with $\mathrm{CO}_{2}$ content of 10-40\% (vol.) was used in all experiments as gas phase. Studies were carried out with microporous membranes with internal selective layer and average pore diameter of $0.5 \mu \mathrm{m}$ and $2.6 \mu \mathrm{m}$. For the membrane with $0.5 \mu \mathrm{m}$ pores gas consumption (depending on liquid consumption) was $26.5-101.4 \mathrm{l} / \mathrm{h}$ (which was corresponding to pressure of 0.062-0.064 MPa), for the membrane with $2.6 \mu \mathrm{m}$ pores gas consumption was $25.8-100.7 \mathrm{l} / \mathrm{h}$ (which was corresponding to pressure of 0.062-0.064 MPa). As liquid phase $\mathrm{CaOH}$ solutions with the following concentrations were used: $0.030 ; 0.040 ; 0.050 ; 0.060 ; 0.070 \mathrm{kmole} / \mathrm{m}^{3}$ (for the memebrane with $\mathrm{d}_{0}=0.5 \mu \mathrm{m}$ ) and $0.010 ; 0.014 ; 0.018 ; 0.024 ; 0.030 \mathrm{kmole} / \mathrm{m}^{3}$ (for membrane with $\mathrm{d}_{0}=$ $2.6 \mu \mathrm{m})$. Those alkali concentrations were selected on the condition that, from one point of view to provide sufficient effectiveness of chemical reaction, from another point of view - to ensure necessary sensitivity for measuring equipment. Consumptions of liquid during experiments were changing in range $77-300 \mathrm{l} / \mathrm{h}$, which corresponds to speeds of $0.7-3.0 \mathrm{~m} / \mathrm{s}$. Definition of a volume of consumed $\mathrm{CO}_{2}$ was carried out by means of measuring of final concentration of alkali in the solution, which was coming out of module, by means of electronic device for measuring of $\mathrm{pH}$.

In order to carry out microbubling process memrbrane chemisorption device is designed (Figure 2), which uses membrane module made of ceramics. It consists of steel cylinder-shaped hull with $750 \mathrm{~mm}$ length and $\varnothing 50 \times 3$ $\mathrm{mm}$ diameter, inside the hull tubular ceramic membrane is installed. Direct contact between gas and liquid phases occurs in membrane module, which results in formation of fine dispersion of bubbles. Gas phase (mixture of $\mathrm{CH}_{4}$ from $\mathrm{CO}_{2}$ and $\mathrm{H}_{2} \mathrm{~S}$ ) is fed with a required pressure inside the body from inside of membrane. Liquid phase is coming inside in ceramic membrane. 


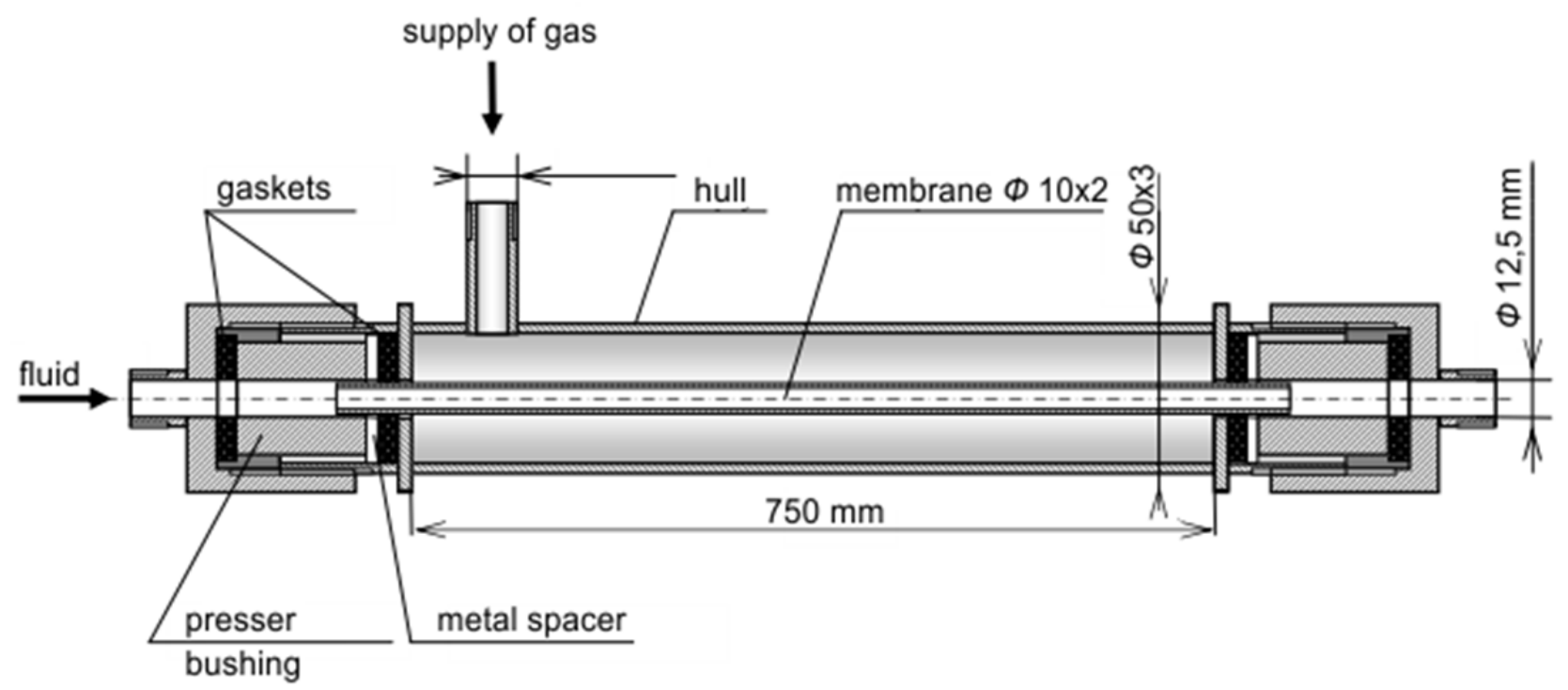

Figure 2. Membrane module for microbubling purification of biogas from $\mathrm{CO}_{2}$

The experimental device consists of chemasorber (1) for carrying out of microbubbling process, vat (2), vortex pump (3) of first level of fire safety, closing $(4,5,6,7,8)$ and regulating $(9,10)$ valves, measuring and control devices (Figure 3).

Gas mixture containing methane, $\mathrm{CO}_{2}, \mathrm{H}_{2} \mathrm{~S}$ and other impurities is coming to the zone between tubes of chemasorber (1) through pipeline (T1), it is coming inside of pores of tubular ceramic microfiltering membrane and is coming out into the internal zone in a form of microbubles. Formed microbubles are continuously washed out by flow of water suspension of $\mathrm{CaO}$, containing microbubles. In further, suspension together with bubbles returned to the vat (2) by means of vortex pump (3) with the following parameters: flow $0.001 \mathrm{~m}^{3} / \mathrm{s}$, manometric head $16 \mathrm{~mm}$ of water column, rotation speed 24.15 rotations/s. The selected pump is of explosion-proof version.

$\mathrm{CaO}$ content in the suspension is $10-20 \%$ (mass). Content of $\mathrm{CO}_{2}$ in gas mix is measured in input (QI,1) and output $(\mathrm{QI}, 2)$ by device for measuring gas concentration $\mathrm{pH}$ of media (QI,3, $\mathrm{pH})$ is measured in the vat (2). Pressure is measured at input of gas into the chemasorber (1) by manometer (PI,4). Flow of suspension in at input of chemasorber (1) by means of rotameter (FI,5). Volumetric flow of the suspension with bubbles is $0.5 \div 1$ $1 / \mathrm{s}$.

$\mathrm{CaO}$, which is contained in suspension, before complete transformation into carbonate can purify $0.8 \mathrm{~m}^{3}$ of gas mixture, containing $50 \%(\mathrm{vol} /)$ of $\mathrm{CO}_{2}$.

In the vat (2) level of suspension is also measured by water-gauge glass (LI,6), bottom pressure is measured by manometer (PI,7), pressure above gas-liquid layer is also measured (PI,8).

Filling of the vat (2) is carried out through valve (7) by the pump (3) with closed valves $(5,6,8,10)$. 


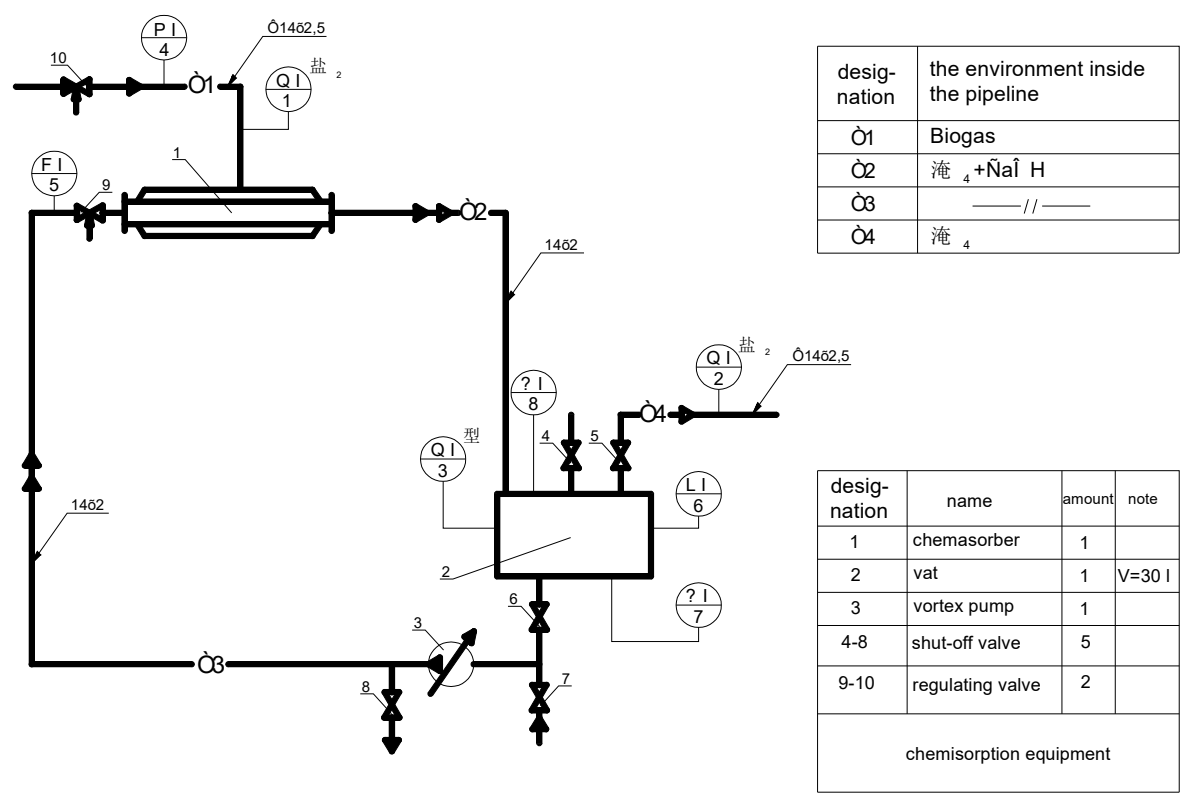

Figure 3. Process flow diagram of microbubling purification from $\mathrm{CO}_{2}$ of gas mixture containing $\mathrm{CH}_{4}$

For emptying of the vat (2) from used suspension the pump is used (3) with open valves $(6,8)$ and not fully closed valve (10), other valves are closed.

The room where the device is operated there is an instrument for a measurement of $\mathrm{CH}_{4}$ concentration with alarming, when critical concentration is reached.

As a results of experiments for study of interphase mass transfer, relationships between specific interphase surface area in the device and mass transfer coefficient in gas phase andspeed of liquid in channel of membrane, also value of interphase flow of absorbed substances depending on speed of liquid and concentration of active part of absorber is defined.

Figure 4 presents relationship between specific interphase surface area and speed of liquid for both used membrane. In the both cases the value of specific interphase surface is increasing with increase of speed up to values of $\omega$ approximately $2 \mathrm{~m} / \mathrm{s}$. Further increase of speed of liquid up to $3 \mathrm{~m} / \mathrm{s}$ doesn't lead to a signifficant increase of interphase surface. As for value of $a$ itself, for membranes with average pore diameter of $0.5 \mu \mathrm{m}$ it is in a range of $18000-30000 \mathrm{~m}^{-1}$, for average pore diameter of $2.6 \mu \mathrm{m}$ it is in a range of $7700-19200 \mathrm{~m}^{-1}$.

An increase of specific interphase surface with an increase of speed of liquid can be explained by means of features of hydromechanics of microbubling process, in particular, decrease of sizes of moving microbubbles, because of increase of resistance stress of incoming flow of liquid during their growth. At the same time, because size of formed microbubbles depedns on sizes of pores of membranes, than for membrane with $d_{0}=0.5 \mu \mathrm{m}$ specific interphase surface is bigger then for a membrane with $d_{0}=2.6 \mu \mathrm{m}$. 


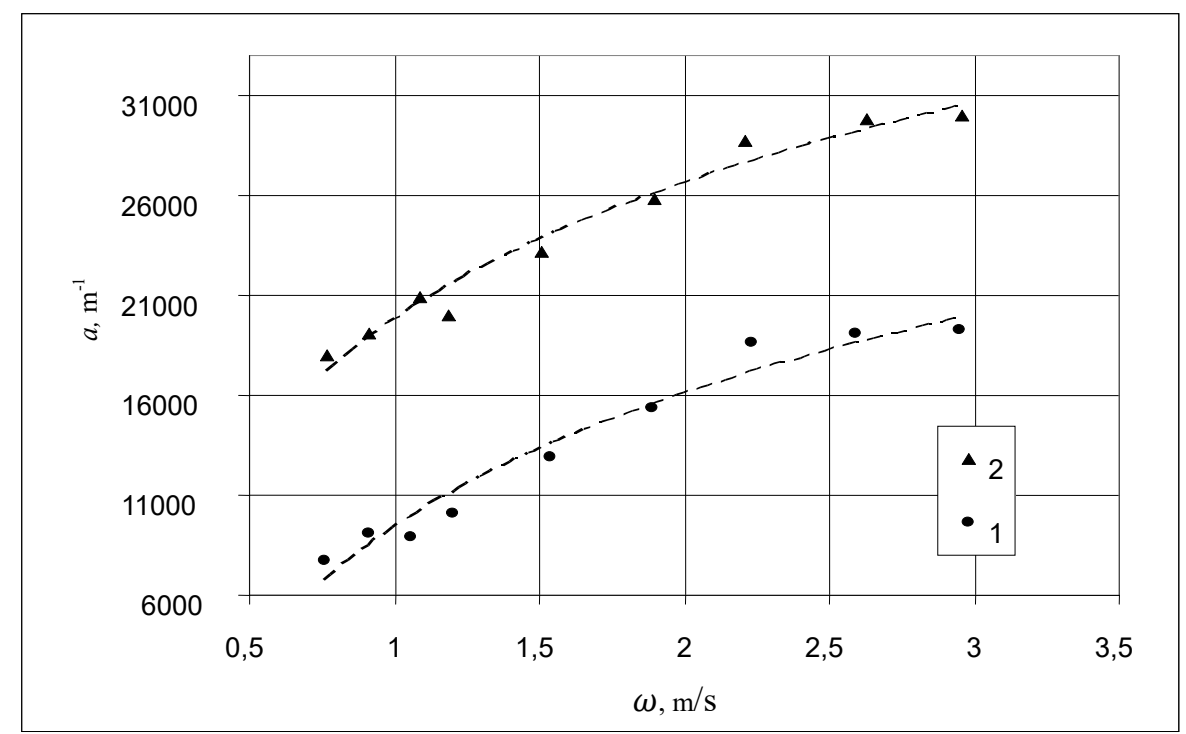

Figure 4. Relationship of specific surface of phase contact for $\mathrm{CO} 2$ and speed of liquid.

1) membrane with $\mathrm{d}_{0}=2.6 \mu \mathrm{m}$; 2) membrane with $\mathrm{d}_{0}=0.5 \mu \mathrm{m}$.

Relationship between interphase flow of carbond dioxide (kmole/s) from speed of liquid is presented in Figure 5.From the Figure it can be seen, that for both used membranes in all cases there is virtually linear increase of value $M$ in the studied range of speeds $(0.5-3 \mathrm{~m} / \mathrm{s})$. According to the obtained data, for a membrane with $\mathrm{d}_{0}=0.5$ $\mu \mathrm{m}$ during chemisorption by alkali solution with $0.07 \mathrm{kmole} / \mathrm{m}^{3}$ concentration $\mathrm{M}$ increases from $20 \cdot 10^{-8}$ to $70 \cdot 10^{-8} \mathrm{kmole} / \mathrm{s}$; for a membrane with $\mathrm{d}_{0}=2.6 \mu \mathrm{m}$ mass flow is also increase with an increase of speed, however, both $\mathrm{M}$ and speed of its increase are less as compared to the previous case: from $5 \cdot 10^{-8}$ to $20 \cdot 10^{-8} \mathrm{kmole} / \mathrm{s}$ during chemisorption by alkali solution with $0.07 \mathrm{kmole} / \mathrm{m} 3$ (Figure 5). Because in a case of chemisorption with significantly fast chemical reaction hydrodynamics of bottom layers of liquid doesn't seriously influence mass transfer coefficient in liquid phase, an increase of interphase flow with an increase of speed, presumably, is caused by two factors: first, increase of specific interphase surface, second, an increase of mass transfer coefficient in gas phase.

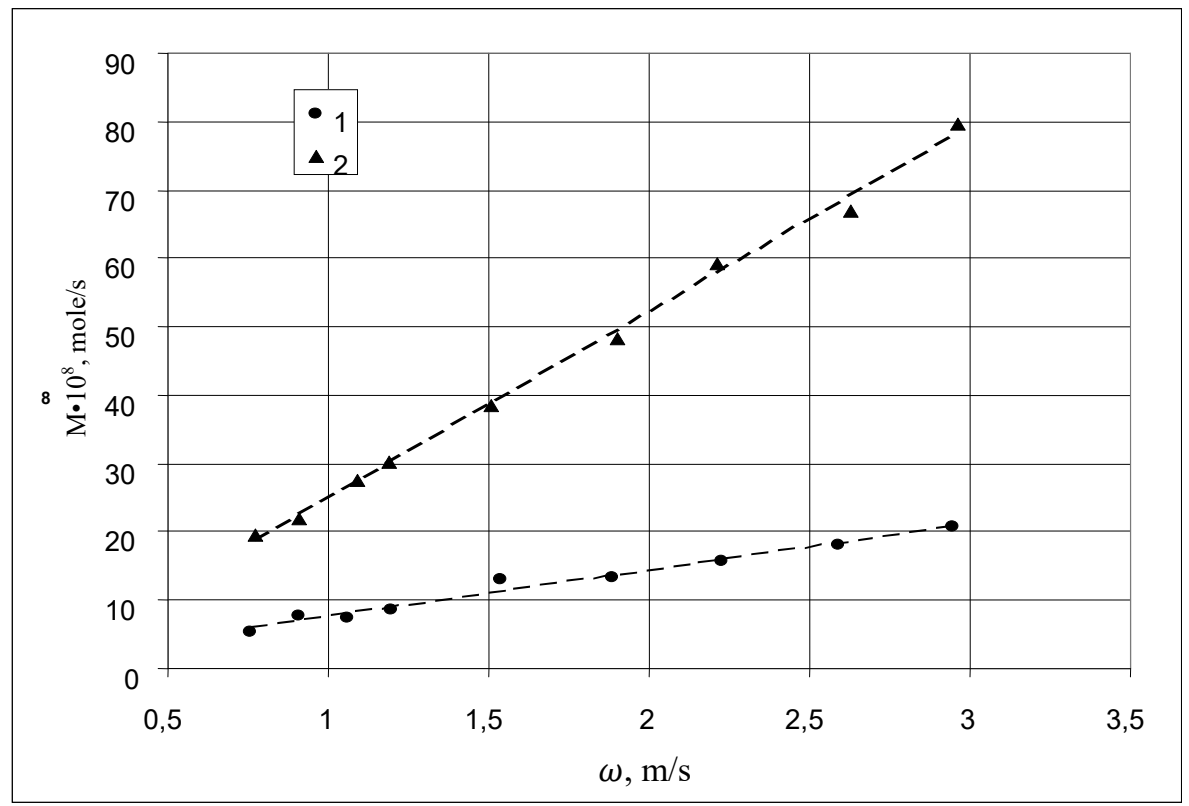

Figure 5. Relationship of interphase flow and speed of liquid

1) membrane with $\left.\mathrm{d}_{0}=2.6 \mu \mathrm{m}\left(C_{B}=0.03 \mathrm{kmole} / \mathrm{m}^{3}\right) ; 2\right)$ membrane with $\mathrm{d}_{0}=0.5 \mu \mathrm{m}\left(C_{B}=0.07 \mathrm{kmole} / \mathrm{m}^{3}\right)$. 
Let's discuss relationships of interphase flow of carbon dioxide from alkali concentration. From expression (17) with known values of $a$ and $k_{y}$ interphase flow can be described as follows:

$$
M=\left(\frac{1}{k_{y}}+\frac{m}{a \sqrt{k_{2} C_{B} D_{C O}}}\right)^{-1} C_{0, G} V_{\text {work }} .
$$

In all cases interphase flow is increasing with an increase of concentration, which can be explained by an increase of mass transfer coefficient in liquid phase, which is calculated using the expression (14). Error in a description of experimental data is in a range $5-20 \%$. Also, it can be seen, that experimental data, obtained with a membrane with pore sizes of $0.5 \mu \mathrm{m}$ conform to the expression (26) better, then data for a membrane with pores of $2.6 \mu \mathrm{m}$ size. Presumably, it is explained by higher error of the method in the second case, as in experiments with a membrane with $d_{0}=2.6 \mu \mathrm{m}$ alkali solutions of lower concentration were used (lower alkali concentrations were selected in order to ensure necessary sensitivity of measuring instruments, because for that membrane due to lower pressure volumetric concentration of $\mathrm{CO}_{2}$ in incoming gas mixture is lower).

The fact that obtained experimental data is in good agreement with the expression (26) may be a good indirect proof of correctness of use of the selected methodology for mass transfer studies.

It is worth mentioning, that in a case of experiments with a membrane with $2.6 \mu \mathrm{m}$ pores, in a case of small concentrations of alkali value of $k_{x}^{\prime} / k_{x}$ is close to the lower boundary of inequality, which can be an indicator of errors in that zone, which are related with that a condition of pseudo-first order of reaction is not satisfied.

\section{Analysis of Adequacy of the Obtained Data}

Further, let's compare membrane microbubbling contactor with other types of devices.

Let's discuss microbubbling layer on a plate and gas-liquid dispersion in membrane contactor, having the same volume and gas content. Specific contact surface in plate-type device depends on design of plate, speed of gas and physical properties of gas-liquid system. For example, mesh plates with comparatively low speeds of gas in zone of cellular foam contact surface is approximately $200 \mathrm{~m}^{-1}$ (Ramm, 1976).

Further increase of gas speed increases contact surface, reaching 800-100 $\mathrm{m}^{-1}$. For concave type of plates $a$ doesn't seriously depend on speed of gas and reaches approximately $1000 \mathrm{~m}^{-1}$ for air-water system and bigger values (up to $4000 \mathrm{~m}^{-1}$ ) for systems with organic liquids. Thus, for place type equipment value of specific area of phase contact is in a range of $200-4000 \mathrm{~m}^{-1}$ and in average is $1000 \mathrm{~m}^{-1}$. From the results of conducted experiments it follows, that contact surface in membrane microbubbling devices depends on membrane characteristics, speed of liquid, gas consumption and, in our case, was in a range from $8000 \mathrm{~m}^{-1}$ to $30000 \mathrm{~m}^{-1}$. It leads to conclusion, that specific interphase surface in microbubbling device, depending on process conditions, will be $8-30$ times higher than in bubbling layer on a plate.

Analysis of main mechanisms of mass transfer with chemical reaction allows to conclude, that during chemisorption mass transfer coefficient in liquid phase both in plate type and membrane type membrane microbubbling device can be calculated using expression (14), thus, values of $k_{x}^{\prime}$ will be comparable.

Calculations of mass-transfer coefficient, which were carried out on a basis of experimental data, shows, that for conditions, studied in the presented paper, mass-transfer coefficient in membrane contactor (calculated for gas phase) has values of $1.6 \cdot 10^{-5}-4.5 \cdot 10^{-5} \mathrm{~m} / \mathrm{s}$ for a membrane with $0.5 \mu \mathrm{m}$ pores and $2.3 \cdot 1^{-5}-4.5 \cdot 10^{-5}$ for a membrane with $2.6 \mu \mathrm{m}$ pores. Mass transfer coefficients in plate-type device, calculated on a condition of equal $k_{x}^{\prime}$ and value $k_{y}=1 \cdot 10^{-3} \mathrm{~m} / \mathrm{s}$ are $4.6 \cdot 10^{-5}-7.5 \cdot 10^{-5} \mathrm{~m} / \mathrm{s}$ and $2.9 \cdot 10^{-5}-5.1 \cdot 10^{-5} \mathrm{~m} / \mathrm{s}$ respectively. Therefore, mass transfer coefficients in plate-type device in the discussed conditions will be 1.1-2.9 times higher than in membrane contactor.

Transformation of expression (26) gives the following:

$$
M=\left(\frac{1}{k_{y}}+\frac{m}{\sqrt{k_{2} C_{B} D_{C O}}}\right)^{-1} a C_{0, G} V_{\text {work }}=k_{y} a C_{0, G} V_{\text {work }},
$$

it can be concluded, that because value of $k_{y}$ membrane device is in average 1.5 times smaller and specific interphase surface is in 8-30 times higher, than in a case of the same working volumes amount of absorbed substances will increase in 5-20 times. It allows to conclude that in order to reach the desired level of absorption, membrane microbubbling device must have 5-20 smaller working volume than plate type device. At that, the following recommendations can be given. Mass transfer coefficient obtained during experiments with both membranes are quite close, but in the same time values of specific interphase surface for a membrane with $d_{0}=0.5 \mu \mathrm{m}$ are in 2-2.5 times bigger. Thus, it can be presumed, that implementation of microfiltering membranes 
with pores less than $1 \mu \mathrm{m}$ will give more significant effect in decreasing sizes of a devices and, consequently, will reduce capital spendings. At that, the most optimal range of speeds of liquid, both from point of view of mass transfer coefficients and specific interphase surface is a range $1.5-2.5 \mathrm{~m} / \mathrm{s}$. At the same time, in a case of use of membrane with $0.5 \mu \mathrm{m}$ pores necessary gas pressure is three times higher, as compared to a membrane with $2.6 \mu \mathrm{m}$ pores. It can lead to significant energy expenses for gas blow off, especially with their expenses. Thus, for design of membrane device for a specific process technical and economic analysis should be carried out in order to find a compromise decision between a selection of type of membranes with smaller pores to reduce sizes of device from one side, and a selection of membranes with bigger pore to reduce necessary pressure from another side.

The following is also should be noted: in the majority of industrial plate-type absorbers gas expenses significantly exceed liquid expenses (Purification of process gases, 1977). However, in membrane contactor that ratio of gas and liquid expenses is intolerable, because it will lead to gas content in dispersion of more than 0.5 . Presumably, it will lead to disturbance of microbubbles formation and change of process parameters (it worse reminding, that in the presented work mass transfer studies were carried out with gas content of $25 \%$ ). Thus, design of membrane microbubbling device on a basis of gas loads, comparable with plate-type devices, would require a significant increase of use liquid absorber which will increase operation expenses and sizes of the device. In that case use of microbubbling contactor would be unreasonable.

That's why the most effective area of application of microbubbling method is processes that don't require high gas loads. Purification of biogas from carbon dioxide is an example of that kind of process.

Use of membrane devices in a process of purification of biological methane from $\mathrm{CO}_{2}$ is extensively studied nowadays (Atchariyawut, et al., 2007), (Al-Marzouqi, et al., 2008), (Yan, et al., 2007), (Zhang, 2006), (Li, \& Chen, 2009), (Mansourizadeh, \& Ismail, 2009). Generally those are devices on a basis of hollow fiber membranes, comprising porous polymer fibers. Absorption in that kind of devices is carried out due to contact of gas through pores with liquid, flowing inside fibers, in a case there is no bubbling, pores are filled with gas (if membrane surface can't been wet) or with liquid (if membrane can be wet) and contact surface in that case depends on a number of fibers and porosity of membrane. Main advantages of that devices are small sizes, high selectivity of operation and absence of operational restrictions, which are characteristic for plate-type cap-type devices. That's a comparison of membrane contactors with hollow fiber membranes and microbubbling device from a point of effectiveness of interphase mass transfer is of a big interest.

Calculations of mass-transfer coefficient, which were carried out on a basis of experimental data, shows, that for conditions, studied in the presented paper, mass-transfer coefficient in membrane contactor (calculated for gas phase) has values of $1.6 \cdot 10^{-5}-4.5 \cdot 10^{-5} \mathrm{~m} / \mathrm{s}$ for a membrane with $0 \mu \mathrm{m}$ pores and $2 \cdot 3^{-5}-4.5 \cdot 10^{-5}$ for a membrane with $2.6 \mu \mathrm{m}$ pores. 


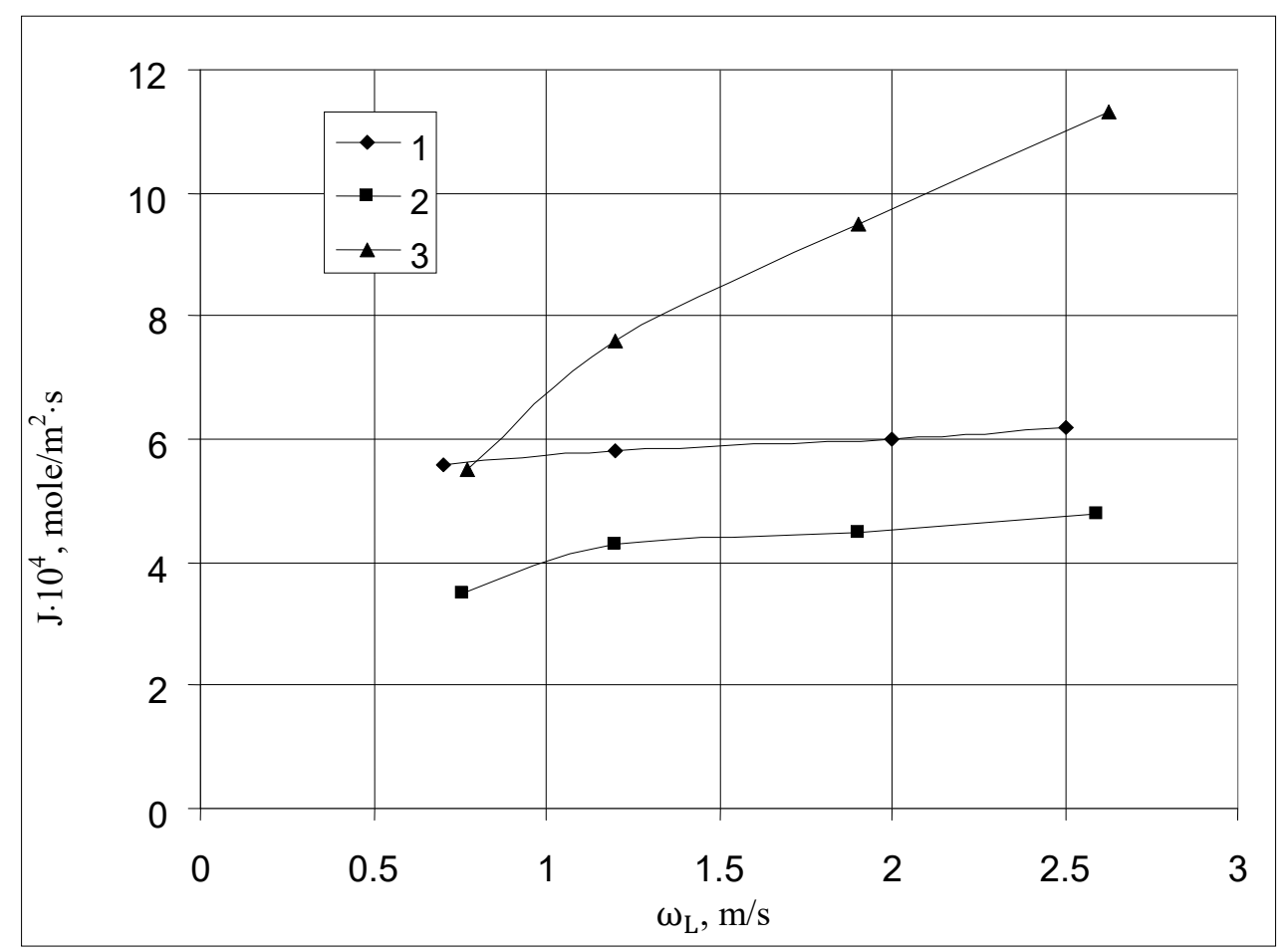

Figure 6. Comparison between specific interphase flow in the microbubbling device and membrane contactor with hollow fiber membranes during chemisorption of $\mathrm{CO}_{2}$ water solution of $\mathrm{CaO}\left(C_{B}=0.1 \mathrm{kmole} / \mathrm{m}^{3}\right)$

1) Hollow fiber membrane with $d_{0}=0.2 \mu \mathrm{m}$ (reference data);2) ceramic membrane with $d_{0}=2.6 \mu \mathrm{m} ; 3$ ) ceramic membrane with $d_{0}=0.5 \mu \mathrm{m}$.

The Figure 6 shows experimental data on specific interphase flow of $\mathrm{CO}_{2}$ in microbubbling device and in membrane contactor with polymer hollow fiber membranes with comparable conditions. As it can be seen from the Figure, in a case of use of membranes with a diameter $2.6 \mu \mathrm{m}$ has specific flow is $3.5 \cdot 10^{-4}-4.8 \cdot 10^{-4}$ mole $/ \mathrm{m} 2 \cdot \mathrm{s}$, which is very close to the data for hollow fiber membrane $\left(5.6 \cdot 10^{-4}-6.2 \cdot 10^{-4} \mathrm{~mole} / \mathrm{m}^{2} \cdot \mathrm{s}\right)$. In the case with the membrane with $0.5 \mu \mathrm{m}$ pores specific flow varies from $5.6 \cdot 10^{-4}$ to $11.310^{-4} \mathrm{~mole} / \mathrm{m}^{2} \cdot \mathrm{s}$ and exceeds values for hollow fiber membrane, especially at speeds of liquid of $1.5-2.5 \mathrm{~m} / \mathrm{s}$. That allows to conclude that in a case of use of microporous membranes microbubbling device may have advantages in terms of efficiency of mass transfer as compared to devices with hollow fiber membranes. In addition, the majority of polymer hollow fiber membranes lose their performance characteristics at elevated temperatures, in contrast to ceramic membranes (Koonaphapdeelert, \& Zhentao, 2009), which indicates another important advantage of microbubbling device.

On a basis of the obtained data the following practical recommendations can be made. In order to obtain the largest phase interface surface, membranes made from ceramics and glass with a little value of roughness and average pore size equal to $0.2-3.0 \mu \mathrm{m}$ should be implemented in a design of mass transferring microbubling equipment. The optimal range of liquid's speed for the process is $1.5-2.5 \mathrm{~m} / \mathrm{s}$. Ratio of flows of gas and liquid in the equipment must provide that gas content of a dispersion do not exceed $30 \%$; in the opposite case mechanism of a formation of microbubbles can be compromised, which leads to a decrease of specific phase interface surface in the equipment. During a selection of sizes of membrane pores a compromise solution must be found, which considers both an increase of phase interface surface, leading to a decrease of a working volume of the equipment, and an increase of pressure in the equipment, which leads to increased energy expenses. Chemical absorbent shall be used for higher efficiency of mass transfer.

The results obtained in the presented study can be practically applied in the following fields:

- Definition of specific phase interface surface in membrane microbubling equipment;

- Definition of sizes of microbubbles in membrane floatation equipment; 
- Definition of main mass transfer parameters in membrane equipment with gas-liquid contact (absorbers, chemical reactors, fermenters, etc.). Membrane microbubling equipment can be applied for purification of various multi component gas mixtures (e.g., purification of exhaust gases from carbon dioxide), for various chemical reactions (hydrogenation, oxidation) and for purification of waste waters from various contaminants (organic colorants, oils, iron oxides, etc.).

\section{Conclusion}

The developed technology biogas purification from carbon dioxide gas is proposed. Mass transfer in finely dispersed gas-liquid systems is experimentally investigated. Fine gas-liquid dispersions were created by means of microbubbling method through tubular microfiltering ceramic membranes using incoming liquid. Processes of absorption and chemisorption during microbubbling in mobile liquid phase are studied. Mass transfer coefficients are identified, specific interphase surfaces and interphase flows in microbubbling device during absorption of carbon dioxide from its mixtures with methane and water suspension of $\mathrm{CaO}$ are identified. The adequacy of model is proved by experiments of the authors and comparisons with reference experimental data. It is demonstrated, that value specific interphase surface during microbubbling is 8-30 times higher, than in the normal bubbling, which leads to a significant reduction in working volume of a device with the same efficiency. A comparison with membrane hollow fiber contactors shows that using of ceramic membranes allows to substantially increase value specific interphase flow in the microbubbling device and it is comparable or higher than in a case of hollow fiber contactor.

As it was noted, all presented conclusions are based on the provisions of film model of substance's transfer. However, penetration model also can be used for a description of membrane microbubbling method. Therefore, a comparison of relationships obtained by film and penetrations model is of big interest. Existing theories regarding chemisorption, even though they can't be considered complete, provide sufficiently reliable results for a case of fast nonreversible reactions of first and pseudo-first order. At the same time, in fact, all models of mass transfer are demonstrating similar values for mass transfer coefficient for chemisorption. However, because of disadvantages characteristic to existing models of transfer, for accurate prediction of $k_{x}^{\prime}$ it is necessary to have experimental data on $k_{x}$. For the verification of the conditions on pseudo-first order reaction (condition 15) it is planned to conduct experiments on physical absorption of pure $\mathrm{CO}_{2}$ by water, on the same membranes and in the same speed range of liquid and gas consumptions as in experiments on chemisorption. On the basis of the obtained data it will possible to calculate values of mass transfer coefficient in liquid phase during physical absorption $k_{x}$.In addition the study physical absorption of carbon dioxide may allow a verification of a satisfaction of the condition (15).

\section{Acknowledgments}

The presented paper has been created with a help of grant the Ministry of Education and Science of the Republic of Kazakhstan in a state program "Grant funding for research", for sub priority: "The renewable sources of energy (wind, and hydropower, biofuels and photoelectricity)", on the topic "The development of technologies and simulation of process microbubbling purification of biogas with a view to obtain highly-concentrated methane from renewable sources of energy". We would like to express gratitude to our colleagues from D. Mendeleev University of Chemical Technology of Russia, doctors of technical sciences, Professors E.A. Dmitriev, A.M.Trushin, candidate to doctor of technical sciences, assistant professor I.K. Kuznetsova.

\section{References}

Al-Marzouqi, M., El-Naas, M., Marzouk, S., Al-Zarooni, M., Abdullatif, N., \& Faiz, R. (2008). Modeling of $\mathrm{CO}_{2}$ absorption in membrane contactors. Sep.andPurif. Tech., 3(59), 286-295. 293. http://dx.doi.org/10.1016/j.seppur.2007.06.020

Astarita, D. (1971). Mass transfer with chemical reaction. Moscow: Chemistry.

Atchariyawut, S., Jiraratananon, R., \& Wang, R. (2007). Separation of $\mathrm{CO}_{2}$ from $\mathrm{CH}_{4}$ by using gas-liquid membrane contacting process.Journal of membrane science, 304, 163-172. http://dx.doi.org/10.1016/j.memsci.2007.07.030

Biogas plants in Europe: A practical handbook. (2007). Springer.

Bobilev, V. (2003). Physical properties the most well-known chemical substances. Moscow: D. Mendeleev University of Chemical Technology of Russia.

Cho, S., Kim, J. Y., Chun, J., \& Kim, J. D. (2005). Ultrasonic formation of nanobubbles and their zeta-potentials in aqueous electrolyte and surfactant solutions. Colloids and surfaces A:Physicochem. Eng. Aspects, 269, 
28-34. http://dx.doi.org/10.1016/j.colsurfa.2005.06.063

Christensen, T., Christensen, T., Cossu, R., \& Stegmann, R. (1996). Landfilling of Waste: Biogas (1st ed.). Publisher: Taylor \& Francis.

Concise Encyclopedia of Bioresource Technology. (2004). CRCPress. http://dx.doi.org/ 10.5860/choice.42-3775

Danckwerts, P. (1973). Gas-liquid reaction. Moscow: Chemistry.

Darmana, D., Henket, R., Deen, N., \& Kuipers, J. (2007). Detailed modeling of hydrodynamics, mass transfer and chemical reactions in a bubble column using a discrete bubble model: chemisorption of $\mathrm{CO}_{2}$ into $\mathrm{NaOH}$ solution, numerical and experimental study. Chem. Eng. Sci., 62, 2556-2567. http://dx.doi.org/10.1016/j.cec.2007.01.065

Deublein, D., \& Steinhauser, A. (2008). Biogas from Waste and Renewable Resources. Publishing House: Wiley. http://dx.doi.org/ 10.1002/9783527621705

Ditnerski, Yu., Brikov, V., \& Kaigramanov, G. (1991). Membrane separation of gases. Moscow: Chemistry.

Eder, B., \& Schulz, H. (2006). Biogas Praxis. Translated in Russian language. Biogas installations. Practical guide.

Hatta, S. (1932). On the absorption velocity of gases by liquids.Tech. Repts. Tohoku Imp. Univ., 10, 119-128.

Hobler, T. (1964). Mass transfer and adsorption. Moscow: Chemistry.

Kim, J., Song, M., \& Kim, J. (2000). Zeta potential of nanobubbles generated by ultrasonication in aqueous alkyl polyglycoside solutions. J. Colloids Interf. Sci., 223, 285-291. http://dx.doi.org/10.1006/jcis.1999.6663

Kimura, S., \& Walmet, G. (1980). Fuel Gas Purification with Permselective Membranes Separat. Sci. and Technol., 4(15), 1115-1133. http://dx.doi.org/10.1080/01496398008076290

Koonaphapdeelert, S., Zhentao, W., \& Li, K. (2009). Carbon dioxide stripping in ceramic hollow fiber membrane contactors.Chem. Eng. Sci., 64, 1-12. http://dx.doi.org/10.1016/j.cec.2008.09.010

Krevelen, D., \& Hoftijzer, P. (1958). Micro- and macro- kinetics: general introduction to the symposium. Chem. Eng. Sci., 1-2(8), 5-17. http://dx.doi.org/10.1016/0009-2509(58)80032-9

Kukizaki, M., \& Goto, M. (2006). Size control of nanobubbles generated from SPG membranes.Journal of membrane science, 281, 386-396. http://dx.doi.org/10.1016/j.memsci.2006.04.007

Kukizaki, M., \& Goto, M. (2006). Spontaneous formation behavior of uniform-sized microbubbles from SPG membranes in the absence of water-phase flow. Colloids and surfaces A: Physicochem. Eng. Aspects, 14097. http://dx.doi.org/10.1016/j.memsci.2006.04.007

Li., J., \& Chen, B. (2005). Review of $\mathrm{CO}_{2}$ absorption using chemical solvents in hollow fibers membrane contactors.Separation Purification Tech., 41, 109-122. http://dx.doi.org/10.1016/j.seppur.2004.09.008

Loubiere, K., \& Hebrard, G. (2004). Influence of Liquid surface tension (surfactants) on bubble formation at rigid and flexible orifices.Chemical Engineering and Processing, 43, 1361-1369. http://dx.doi.org/10.1016/j.cep.2004.03.009

Maalej, S., Benadda, B., \& Otterbein, M. (2003). Interfacial area and volumetric mass transfer coefficient in a bubble reactor at elevated pressure.Chem. Eng. Sci., 58, 2365-2376. http://dx.doi.org/10.1016/s0009-2509(03)00085-x

Mansourizadeh, A., \& Ismail, A. (2009). Hollow fiber gas-liquid membrane contactors for acid gas capture: a review.Journal of Hazardous Materials, 171, 38-53. http://dx.doi.org/10.1016/j.jhazmat.2009.06.026

Painmanakul, P., Loubiere, K., \& Hebrard, G. (2005). Effect of surfactants on liquid-side mass transfer coefficients. Chemical Engineering science, 60, 6480-6491. http://dx.doi.org/10.1016/j.cec.2005.04.053

Pohorecki, R., \& Moniuk, W. (1988). Kinetics of reaction between carbon dioxide and hydroxyl ions in aqueous electrolyte solution.Chem. Eng. Sci., 43, 1677-1684. http://dx.doi.org/10.1016/0009-2509(88)85159-5

Ramm, V. (1976). Gas absorption. Moscow: Chemistry.

Richardson, J., \& Coulson, J. (1999). Chemical Engineering (6th ed.). Vol. 1. Oxford: Butterworth-Heinemann.

Rodriguez, R., \& Rubio, J. (2003). New basis for measuring bubbles size distribution. Minerals Engineering, 8(16), 757-765. http://dx.doi.org/10.1016/S0892-6875(03)00181-X

Rutz, D., \& Janssen, R. (nd.). Biofuel Technology Handbook. Dipl.-Ing. WIP Renewable Energies, Sylvenstein str. 
Munchen, Germany. Retrieved December 26, 2014, from www.wip-munich.de

Semenova, T., \& Leitesa, I. (1977). Purification of process gases (2nd ed). Moscow: Chemistry.

Sharma, M., \& Danckwerts, P. (1970). Chemical methods of measuring interfacial area and mass transfer coefficient in two-fluid systems. British Chemical Eng., 15(4), 522.

Unger, E., Matsunaga, T., Schumann, P., \& Zutshi, R. (2003, April). Microbubbles in molecular imaging and therapy. Medicamundi, 47(1), 58-65.

Versteeg, G., \& Swaaij, W. (1988). Solubility and diffusivity of acid gases $\left(\mathrm{CO}_{2}\right.$ and $\left.\mathrm{N}_{2} \mathrm{O}\right)$ in aqueous alkaloamin solutions. Journal of Chem. Eng. Data, 33, 29-34. http://dx.doi.org/ 10.1021/je00051a011

Yan, S., Fang, M., Zhang, W., Wang, S., Xu, Z., Luo, Z., \& Cen, K. (2007). Experimental study on the separation of $\mathrm{CO}_{2}$ from flue gas using hollow fiber membrane contactors without wetting. Fuel Processing Tech., 88, 501-511. http://dx.doi.org/10.1016/j. fuproc.2006.12.007

Zhang, H., Wang, R., Liang, D., \& Tay, J. (2006). Modeling and experimental study of $\mathrm{CO}_{2}$ absorption in a hollow fiber membrane contactors. Journal of membrane science, 279, 301-307. http://dx.doi.org/10.1016/j.memsci.2005.12.017

Zong, Y., Wan, M., Wang, S., \& Zhang, G. (2006). Optimal design and experimental investigation of surfactant encapsulated microbubbles. Ultrasonics, 44, 119-122. http://dx.doi.org/10.1016/j.ultras.2006.06.005

\section{Copyrights}

Copyright for this article is retained by the author(s), with first publication rights granted to the journal.

This is an open-access article distributed under the terms and conditions of the Creative Commons Attribution license (http://creativecommons.org/licenses/by/3.0/). 